\title{
PARTICIPACIÓN Y REPRESENTACIÓN SINDICAL FEMENINA EN COMISIONES ObRERAS
}

(1970-1982)

\author{
$M^{a}$ Teresa López Hernández \\ Universidad de Salamanca \\ mtlopez@usal.es
}

Recibido: 08-01-09

Aceptado: 02-02-09

\section{Resumen}

El fin de la dictadura en España trajo consigo un cambio legislativo en el que se recogía el principio de igualdad reconocido por la Constitución. La legislación laboral eliminó la discriminación favoreciendo los mismos derechos para los trabajadores independientemente de su sexo. Sin embargo, en la práctica, continuaron existiendo las diferencias según el trabajador fuera hombre o mujer. La actuación sindical, estuvo más preocupada por los problemas económicos y políticos que por las reivindicaciones específicas femeninas, siempre relegadas para otro momento.

Palabras clave: principio de igualdad, discriminación, actuación sindical, reivindicaciones femeninas.

\begin{abstract}
The end of dictatorship in Spain brought along a legislative change, in which was included the principle of equality, recognized by the Spanish Constitution. Labor laws eliminated discrimination favoring the same rights for all workers regardless the gender. However, discriminatory measures based on the sex of workers continued. Trade-unions
\end{abstract}


were more concerned with political and economic issues than specific female claims, which were always put off.

Key words: principle of equality, discriminatory, Trade-unions, feminist claims.

\section{Introducción}

La movilización social contra el régimen de Franco se había iniciado en los años 60 con luchas laborales por las reivindicaciones económicas, a las que se unieron las de varios grupos sociales, estudiantes, asociaciones de vecinos, agrupaciones de amas de casa, y asociaciones profesionales, que veían en estas manifestaciones la vía para demostrar que el Régimen que se había instaurado en España no era aceptado por una parte de la población y además no daba más de sí1.

Las mujeres se incorporaron a estas luchas, decía Mundo Obrero (publicación periódica del Partido Comunista), tratando de reorientarlas hacia la acción política: "deseosas de hacer algo contra la dictadura y a favor de sus víctimas"2.

A medida que aumenta el número de trabajadoras y la oposición al Régimen se incrementa en los últimos años del franquismo, los movimientos femeninos se hacen más visibles, así como también la incorporación de las mujeres a los movimientos obreros y sindicales ${ }^{3}$.

A pesar de que su incorporación fue importante entre 1970-1975, el número de mujeres dentro de los sindicatos era bastante inferior respecto al número de sindicalistas masculinos ${ }^{4}$.

\footnotetext{
${ }^{1}$ Preston, P. (1989): España en crisis: evolución y decadencia del régimen de Franco. México: FCE, pp. 300 y ss.

${ }^{2}$ N.P. (20 de diciembre de 1969): "Más mujeres para el Partido". En Mundo Obrero, p. 7.

${ }^{3}$ Ver Di Febo, Giuliana (1979): Resistencia y movimiento de mujeres en España, 1936-1976. Barcelona: Icaria, pp. 154 y 164-185.

${ }^{4}$ Durán, $\mathrm{M}^{\mathrm{a}}$ Ángeles (1977): Dominación, sexo y cambio social. Madrid: Cuadernos para el Diálogo, p. 216-217.
} 
Las reivindicaciones femeninas eran más importantes, como cabía esperar, en ciertos sectores tradicionalmente feminizados y en aquellas regiones con más industrialización, donde había una conciencia de clase más acusada.

Algunas investigaciones feministas sobre el papel de la izquierda en los partidos y sindicatos, en concreto el Partido Comunista y CC.OO., apuntan a la instrumentación de las mujeres. Lidia Falcón (2000: 127) sostiene que se contó con ellas porque se las necesitaba en la lucha contra el franquismo, pero que no había un verdadero interés por sus problemas ni voluntad de resolverlos, sino que, reproduciéndose en la izquierda los prejuicios sociales y culturales que imperaban contra las mujeres, su participación en los estratos representativos de las estructuras sindicales no fue alentada ${ }^{5}$.

\section{Actividad sindical de las trabajadoras}

\subsection{El fin del franquismo}

La Gaceta de Derecho Social (órgano de expresión del sindicato CC.OO, que en 1980 pasaría a llamarse Gaceta Sindical) subrayó que la representación sindical de las mujeres en la Organización Sindical Española (O.S.E). - donde el PCE tenía la consigna de infiltrarse - era baja, y disminuía mucho en los niveles más altos de representatividad, dándose el caso de que cuando se presentaban a enlaces sindicales, las propias trabajadoras escogían a menudo a los candidatos masculinos, en la creencia de que defenderían mejor sus intereses ${ }^{6}$.

\footnotetext{
${ }^{5}$ De la misma opinión es $\mathrm{M}^{\mathrm{a}}$ Ángeles Durán: La posición ideológica y social de los sindicatos afectaba a la concepción y aceptación del trabajo femenino que estos tenían. Durán, Ma Ángeles (1972): El trabajo de la mujer en España. Un estudio sociológico. Madrid: Tecnos, pp. 45 y ss.

${ }^{6}$ En Barcelona solamente son enlaces sindicales 4.000 mujeres de las 360.000 que trabajan. Iglesias, Ma Antonia (octubre 1972): "Liberación de la Mujer Obrera". En Gaceta de Derecho Social, $\mathrm{n}^{\mathrm{o}} 17$, p. 23.
} 
El cuadro que a continuación reproducimos, publicado en marzo en la Revista mencionada anteriormente, en el marco de un artículo de Carmen Rioboo (1973: 14) sobre los enlaces sindicales, nos permite un balance cuantitativo del número de mujeres que ostentaban puestos de representación en 1973.

\begin{tabular}{|l|c|}
\hline \multicolumn{2}{|c|}{ REPRESENTACIÓN FEMENINA } \\
\hline Vocales Nacionales & 324 \\
\hline Vocales Provinciales & 6.875 \\
\hline Vocales Locales & 13.321 \\
\hline Vocales Jurados & 4.599 \\
\hline Enlaces & 20.843 \\
\hline
\end{tabular}

1. Fuente: Rioboo, Carmen. (marzo 1973): "Las enlaces Sindicales". En Gaceta de Derecho Social, $n^{\circ} 22, p .14$.

Las provincias con más representación sindical femenina eran las más conflictivas en el terreno laboral, y las que tenían un nivel de desarrollo económico más alto.

\begin{tabular}{|l|c|}
\hline \multicolumn{2}{|c|}{ ENLACES SINDICALES POR PROVINCIAS } \\
\hline Barcelona & 4.692 \\
\hline Madrid & 3.486 \\
\hline Valencia & 1.324 \\
\hline Alicante & 1.312 \\
\hline Vigo & 957 \\
\hline Zaragoza & 582 \\
\hline Guipúzcoa & 552 \\
\hline Sevilla & 513 \\
\hline Vizcaya & 513 \\
\hline Málaga & 481 \\
\hline
\end{tabular}

2. Fuente: Rioboo, Carmen. (marzo 1973): “Las enlaces sindicales”. En Gaceta de Derecho Social, $n^{o} 22, p .14$. 
La representación era mayor en los sectores laborales más feminizados

\begin{tabular}{|l|c|}
\hline \multicolumn{2}{|c|}{ ENLACES FEMENINOS POR RAMAS SINDICALES } \\
\hline Textil & 5.643 \\
\hline Metal & 2.000 \\
\hline Actividades Diversas & 1.766 \\
\hline Asistencia Sanitaria & 1.454 \\
\hline Industrias Químicas & 1.326 \\
\hline Enseñanza & 1.085 \\
\hline Hostelería & 951 \\
\hline
\end{tabular}

3. Fuente: Rioboo, Carmen. (marzo 1973): "Las enlaces sindicales". En Gaceta de Derecho Social, $n^{\circ} 22$, p. 14.

Según Carmen Rioboo, (1973: 14) el que en las provincias más pobres económicamente y marginadas de la evolución del resto del país, se encuentran muy pocas mujeres con actividad sindical, respondía a una mentalidad más tradicional que impedía a las mujeres interesarse en su proyección social. Si en Marzo de 1973 la articulista había dado la voz de alarma sobre la escasez de enlaces sindicales femeninos, en 1975 la Gaceta apunta a lo que entiende como factores explicativos de una débil representación tanto personales como sociales y sindicales. Aseguraban las propias mujeres implicadas al respecto que se sentían inferiores frente al hombre en el mundo laboral y en el sindical más, que en las elecciones se solían presentar sólo hombres, y que, cuando había mujeres enlaces y había que hacer una consulta, se la hacían al enlace masculino.

"Las trabajadoras eran conscientes de que había otros "handicaps" de difícil remoción, fruto de difusos prejuicios y la mentalidad patriarcal, que hacían que los problemas específicamente femeninos no se tuvieran en consideración o que la mayoría de los hombres aceptara la segregación laboral femenina por estimar que el salario femenino era un mero apoyo y no el sostén del hogar. Si las mujeres le dedican mucho tiempo al sindicato se les acusa de ser malas 
madres, cosa que no ocurría en el caso de los hombres. Era la propia familia, el novio o el marido los que frenaban en muchas ocasiones la implicación de las mujeres en las tareas de representación"7.

En general los sindicalistas se interesaban poco por afrontar problemas que entendían que eran de facto resueltos, mejor o peor, por las mujeres, que consideraban de débil potencial clientelar:

"En las plataformas se han incluido, en muchas ocasiones, las guarderías infantiles y luego se han quitado, porque hay otras cosas más importantes y de mayor urgencia en estos momentos $\mathrm{y}$, sobre todo, que unirían más" ${ }^{\prime 8}$.

Paradójicamente, este desinterés estaba empezando antes de la muerte de Franco a mover a algunas trabajadoras con conciencia de género a consolidar su presencia en los puestos de representación sindical:

"Las mujeres se sienten menos reconocidas que los hombres a nivel sindical y a nivel de trabajo. Pero [...] sólo cuando las mujeres estén ampliamente representadas en los sindicatos podrán hacer comprender la importancia de sus problemas y arrastrar a los trabajadores con ellas. [...] Es preciso llegar a que las mujeres sean escuchadas como los hombres consideradas como militantes responsables"9.

\footnotetext{
${ }^{7}$ F.B.P. (trad.) (agosto-septiembre 1975): "Una historia de mujeres" y "En la fábrica: compañera; en la casa: criada”. En Gaceta de Derecho Social, n 51-52 separata, pp. 129-132.

${ }^{8}$ Ibídem.

${ }^{9}$ Ibídem.
} 


\subsection{La Transición democrática}

Al término de la Dictadura el cambio político conllevó la legalización de los sindicatos, que unido al apogeo del Movimiento Feminista y al incremento de la participación ciudadana, favoreció la concienciación de que había que crear órganos dentro de los sindicatos para la representación y defensa de los derechos laborales de las mujeres. Participantes femeninas en una asamblea de CC.OO., celebrada en Barcelona en 1976, en la que hubo dos intervenciones - Nuria Casals del Metal de Cataluña y Carmen Fraile del Textil de Madrid - propusieron la creación de un órgano y una política específica hacia las trabajadoras, afirmaba Begoña San José en una entrevista realizada en Salamanca el 22 de mayo de 2007. Había tres posturas respecto a cómo organizar la defensa de la igualdad de las mujeres en CC.OO.: no tener ningún órgano especial, delegar el feminismo al Movimiento Democrático de Mujeres (MDM), o crear órganos específicos que aunaran autonomía e incidencia en el conjunto del sindicato. Dentro de esta última, las sindicalistas vinculadas al MCE y la LCR enfatizaban la autonomía feminista, mientas las vinculadas al PCE defendíamos que las SM fuéramos elegidas igual que el resto de miembros de la Comisión Ejecutiva o Secretariado para incidir más en el conjunto del sindicato ${ }^{10}$.

Las Secretarías de la Mujer de CC.OO. se crearon en 1976 en Madrid, Cataluña, País Valenciano, País Vasco, etc. y en septiembre de 1977 a nivel estatal o confederal $^{11}$.

En las Primeras Jornadas de la Mujer Trabajadora, celebradas en Madrid en febrero de 1977, organizadas por el MDM-Movimiento de Liberación de la Mujeres, y

\footnotetext{
${ }^{10}$ San José, Begoña. (2007): “Las Secretarías Confederales de la Mujer de CC.OO.”. En VV.AA. : Trabajadora: Tres décadas de acción sindical por la igualdad de género (1977-2007). Madrid: Fundación $1^{\circ}$ de Mayo- Secretaría Confederal de la Mujer de CC.OO., p. 77.

Begoña San José desempeñó diversos cargos dentro de las Secretarías: En 1976 fue elegida Secretaria del Sindicato Provincial de Químicas y miembro del Secretariado de la Unión de Madrid de CC.OO., donde desempeñó la recién creada Secretaría de la Mujer, hasta que en septiembre de 1977 pasó al Secretariado Confederal también como responsable de la recién creada Secretaría de la Mujer Confederal, cargo que desempeñó hasta 1981”.

${ }^{11}$ Ibídem., p. 78.
} 
de las que dio noticia la Gaceta, se presentaron tres ponencias: "Problemática general de la mujer trabajadora", "Mujer y movimiento obrero", "La mujer y la legislación española vigente", y se demandó una maternidad libre, consciente y responsable junto a la derogación de la legislación que penalizaba la contracepción y el aborto. A ellas no asistieron representantes de las centrales sindicales, ni siquiera de CC.OO., a pesar de que la mayoría de las asistentes pertenecían a la Confederación Sindical.

Una de las propuestas que se debatió en estas Jornadas fue la creación de un Sindicato de la Mujer para defender mejor sus reivindicaciones, pero fue rechazada por entender que facilitaría que el movimiento obrero se desentendiera de los problemas que afectaban a las trabajadoras, a pesar de que en el movimiento obrero no había una comprensión clara de la problemática de género ${ }^{12}$. Pero el sindicalismo debía asumir la lucha de la mujer y para ello "los hombres tienen que empezar a abandonar sus hábitos de hegemonía en la dirección del movimiento sindical",13.

No obstante, CC.OO. consciente de la nueva fuerza del movimiento feminista y del gran potencial de afiliación de las mujeres, deseaba que la organización en Secretarías fuera un puente entre las feministas y el movimiento sindical ${ }^{14}$.

De hecho, decía Begoña San José (1979: 26-27), que la creación de las Secretarías de la Mujer dentro del sindicato no debía ser un obstáculo para avanzar hacia una confluencia y coordinación de los dos movimientos, a pesar de los prejuicios tradicionales que el movimiento obrero arrastraba hacia las organizaciones de mujeres:

"Hoy la izquierda asume la aportación cualitativa del movimiento feminista al progreso social y político, el papel de las mujeres trabajadoras y de las Secretarías de la Mujer de CC.OO. -como expresión organizada de ellas-

\footnotetext{
12 A. B. (marzo 1977): "Primeras Jornadas de la Mujer Trabajadora. Unidas contra toda la discriminación". En Gaceta de Derecho Social, n 70, pp. 8-9.

${ }^{13}$ Salabert, Miguel (19 febrero 1977): "Primeras Jornadas de la Mujer trabajadora. La vanguardia insurgente del feminismo". En Triunfo, p. 16.

${ }^{14}$ Vanaclocha, M ${ }^{a}$ del Mar (1999): "La mujer en el mundo laboral”. En VV.AA.: Españolas en la Transición: De excluidas a protagonistas (1973-1982). Madrid: Biblioteca Nueva, p. 278.
} 
puede ser trascendental: acercar el movimiento obrero y el movimiento feminista para que ambos se refuercen y complementen mutuamente".

La autora citada (San José, B., 1979: 15) advertía que la falta de sensibilidad de las organizaciones de clase hacia el movimiento feminista, podía orientar a éste a la radicalización y segregación de sus posiciones políticas y sociales. El movimiento de mujeres debía encontrar en el movimiento obrero un aliado que le permitiera realizar sus objetivos en profundidad y amplitud.

También Mundo Obrero asumía ahora una función articuladora del sindicalismo y el feminismo, recogiendo en dos artículos noticias sobre los esfuerzos que a la sazón se estaban realizando y propuestas y sugerencias capaces de darle nueva efectividad.

En la asamblea celebrada por el MDM sobre "Los problemas de la Mujer Trabajadora" en Valencia, informaba uno de los artículos, se abordó entre otros temas el “...encaje de la lucha sindical en el marco general feminista. ¿Cómo coordinar en la práctica sindicalismo y feminismo? "15.

\subsection{Representación femenina en las elecciones sindicales}

Cercanas las elecciones sindicales se intentó dar respuesta a la pregunta formulada. La respuesta aparecía en otro artículo del mismo año en el que se pedía a Comisiones que en las reivindicaciones que formulara se incluyeran planteamientos que asumieran las mujeres, a la par que se creara un sindicato específico y se defendía la doble militancia feminista y sindical de las trabajadoras ${ }^{16}$. Begoña San José (entrevista en Salamanca, mayo de 2007) recuerda que la primera campaña consistió en elaborar

\footnotetext{
15 "Militancia sindical y feminista". (14-20 marzo 1977). En Mundo Obrero, n 10, p. 6.

${ }^{16}$ Bellido, Dulcinea (1-7 diciembre 1977): "Feminismo sindicalista". En Mundo Obrero, no 48, p.16.
} 
una plataforma reivindicativa específica de mujeres e impulsar el aumento de delegadas ante las elecciones sindicales.

En 1978 el Sindicato realizó la convocatoria del Día Internacional de la Mujer Trabajadora junto a las organizaciones feministas, en un intento de acercamiento entre los dos movimientos en su lucha contra la discriminación de la mujer. Una alianza no exenta de tensiones y diferencias, en la que ahora se trataba de evitar a toda costa el enfrentamiento que sólo conduciría a un radicalismo elitista de las organizaciones feministas y un empobrecimiento de la reivindicaciones sindicales femeninas, máxime, teniendo en cuenta que ambos movimientos se decían esencialmente convergentes y complementarios ${ }^{17}$.

A pesar de que el deseo de participar en la elaboración del nuevo marco legal y político supuso un incremento en la participación de partidos políticos y sindicatos, y hubo un aumento de la afiliación de los trabajadores/as a los sindicatos ${ }^{18}$, e incluso ésta fue superior a la masculina en aquellos sectores en los que la segregación de los trabajadoras se materializaba en la ocupación de las categorías más bajas y peor remuneradas $^{19}$, la afiliación sindical femenina fue escasa. La cercanía de las primeras elecciones sindicales sacó a la luz la escasez numérica de las mismas.

En la Unión Sindical de CC.OO. de Madrid el porcentaje de afiliación en 1977 sólo alcanzaba de un $10 \%$ a un $12 \%$, mientras que en otras zonas del Estado no superaba el 15\%. CC.OO. se planteaba potenciar la afiliación y las candidaturas para que reflejaran la proporción de mujeres trabajadoras, pero reconocía las dificultades que había que superar:

\footnotetext{
${ }^{17}$ San José, Begoña (abril 1978): "Mujer y juventud en el sindicalismo de clase". En Gaceta de Derecho Social, $\mathrm{n}^{\circ}$ 84, p. 20.

${ }^{18}$ En CC.OO. el boom de afiliación se produce entre mayo de 1977 y octubre del mismo año y hay tres hechos que lo favorecen: 1.- la legalización de las centrales sindicales, 2.- el fin de la sindicación obligatoria y 3.- la celebración de las primeras elecciones sindicales que suponen una amplia movilización de la sociedad. Soto Carmona, Álvaro (1994): "Comisiones Obreras en la Transición y consolidación democrática”. En David Ruiz (dir.): Historia de Comisiones Obreras (1958-1988). Madrid: Siglo Veintiuno, p. 507.

19 "Las mujeres en la actividad sindical" (junio 1978). En Boletín del Secretariado Confederal de CC.OO. Suplemento monográfico sobre la Mujer Trabajadora, p. 3.
} 
"Es un trabajo en gran medida nuevo y muy complejo, donde se ha dado con frecuencia la falta de coordinación, el recurso socorrido a denunciar situaciones sin proponer verdaderas alternativas, el estancamiento, el desinterés por parte de los compañeros en muchos casos e incluso las contradicciones evidentes en las propuestas que se hacían"20.

Fueron las elecciones de 1978 las que determinaron una nueva actitud de las trabajadoras ante los sindicatos, incrementándose las cifras de afiliadas, como puede apreciarse en el siguiente cuadro, elaborado a partir de una encuesta realizada entre los trabajadores del sector secundario.

Afiliación por sexo entre los asalariados del sector industrial

\begin{tabular}{|l|c|c|}
\hline \multirow{2}{*}{ SINDICATOS } & \multicolumn{2}{|c|}{$\mathbf{1 9 7 8}$} \\
\cline { 2 - 3 } & Varones \% & Mujeres \% \\
\hline CC.OO. & 31,2 & 30,3 \\
\hline UGT & 14,8 & 12,4 \\
\hline USO & 2,4 & 4,4 \\
\hline CNT & 1,5 & 1,9 \\
\hline CSUT & 2,6 & 0,8 \\
\hline SU & 1,7 & 0,6 \\
\hline Otros & 1,9 & 3,2 \\
\hline Total afiliados & 57,6 & 54,7 \\
\hline Total no afiliados & 42,4 & 45,3 \\
\hline NS/NC & --- & --- \\
\hline
\end{tabular}

4. Fuente: Pérez Díaz, Victor. Encuesta a los asalariados del sector industrial (EASI), 1978 y 1980. Fundación del Instituto Nacional de Industria, Programa de Investigaciones Sociológicas. En Pilar Alcobendas Tirado (1993: 152).

${ }^{20}$ Benito, Antonia (noviembre 1977): "La mujer ante las elecciones sindicales. Somos el 28 por 100 de la población activa”. En Gaceta de Derecho Social, nº 78, p. 35. 
Era, sobre todo aquí, en el sector industrial, donde las mujeres tendían ahora a interesarse por los sindicatos en forma similar a los hombres. El 57,4\% de los asalariados de la industria, en efecto, estaban afiliados a una central sindical, siendo la proporción de un 57,6\% para los varones y de un 54,7\% para las mujeres, que a su vez, representaban el $12,3 \%$ del total de los afiliados a centrales sindicales ${ }^{21}$.

Pero una cosa era la afiliación y otra asumir cargos de representatividad en las empresas como delegadas de personal y como miembros del comité de empresa. Había una gran reticencia de las trabajadoras a asumir dicha representatividad.

Si bien la situación era distinta según el sector donde se ubicaran. En las ramas con poca presencia de trabajadoras y una gran tradición de representantes sindicales masculinos, Antonia Benito (1977: 36-37) articulaba que "se podían crear problemas e inclusos enfrentamientos al intentar que las candidaturas recojan una mínima presencia femenina”. No así en los sectores con amplia presencia femenina, donde la mayoría de las personas dirigentes eran mujeres: sirve de ejemplo el Sindicato del Textil de CC.OO. en Madrid en el que más del $90 \%$ de las afiliaciones eran de trabajadoras, al igual que en Sanidad. En otras ramas, como era la de la Administración, la amplia representación femenina se conseguía no sólo por el gran número de afiliadas, sino porque los compañeros "consideran el trabajo sindical como de segunda categoría, prefiriendo plantearse sus reivindicaciones en un terreno más corporativista".

Pero incluso si superaban sus reservas, existían dificultades que hacían más difícil la cobertura de los puestos de representación sindical, como era la amenaza de despidos o la ausencia de elecciones en las empresas muy feminizadas. En el sector textil se añadían otros problemas a la hora de presentar candidaturas: falta de concienciación y temporalidad del trabajo ${ }^{22}$.

\footnotetext{
${ }^{21}$ Alcobendas Tirado, Pilar (1993): Datos sobre el trabajo de la mujer en España. Madrid: C.I.S., p. 151 .

22 Durán, Pilar (diciembre 1980): “Textil: Triunfo en las grandes y pequeñas empresas”. En Gaceta Sindical, no 8 , p. 17.
} 
El número de mujeres que figuraban en las candidaturas sindicales era inferior al que correspondería si se tenía en cuenta el número de componentes femeninos de las plantillas. En 1978, la proporción de delegadas fue del 12\% escaso, menos de la mitad del porcentaje que hubieran podido obtener porque no eran valoradas por los compañeros y compañeras lo que aumentaba su inseguridad.

A nadie podía ocultársele la gran importancia que tenía la participación en la empresa de las trabajadoras como delegadas de personal o miembros del comité de empresa para que no hubiera colisión entre las reivindicaciones generales y las específicamente femeninas, pero las mujeres, además de fracasar cuando lo intentaban, tenían menor disposición a presentarse a dichos cargos que los hombres, facilitándolo tanto la distinta percepción del trabajo existente en los varones y en las mujeres, como en la visión que éstas tenían de su propia problemática ${ }^{23}$.

Participación y disposición a participar en los Comités de empresa por sexos (1980) (Asalariados sector industrial)

\begin{tabular}{|c|c|c|c|}
\hline & $\begin{array}{c}\text { Disposición a } \\
\text { presentarse candidato }\end{array}$ & $\begin{array}{c}\text { Forman parte comité } \\
\text { de empresa }\end{array}$ & Diferencia \\
\hline Hombres (\%) & 26,1 & 11,7 & 14,4 \\
\hline Mujeres (\%) & 11,0 & 4,1 & 7,0 \\
\hline
\end{tabular}

5. Fuente: Pérez Díaz, Víctor. Encuesta a los asalariados del sector industrial (EASI, 1980). Programa de Investigaciones Sociológicas del INI. En Pilar Alcobendas Tirado (1993: 156).

En 1980 sólo el 4,1\% de total de las mujeres asalariadas en el sector industrial formaban parte del comité de empresa y dentro de estos comités, sólo representaban el $5,4 \%$ del total de sus miembros, siendo la proporción de trabajadoras presentes en el sector industrial del $21 \%^{24}$.

\footnotetext{
${ }^{23}$ San José, Begoña (octubre 1980): "Elecciones Sindicales: Uno de cada cuatro electores son mujeres". En Gaceta Sindical, nº 6, p. 40.

${ }^{24}$ Alcobendas Tirado, Pilar: Datos sobre el trabajo de la mujer en España. Op. cit., p. 155.
} 
En concreto, en la empresa 3M, multinacional americana de productos químicos, que daba una imagen de empresa moderna y sin discriminación, de 24 miembros que tenía el Comité de Empresa, sólo 5 eran mujeres, un 20\%, proporción inferior a la de las mujeres de la plantilla, el 28\%, según se recordaba en la Gaceta Sindical $^{25}$.

Aunque la proporción siguió siendo baja sí hubo un aumento desde las elecciones de 1978 a las de 1980. La participación sindical de las mujeres como delegadas aumentó del $11,3 \%$ en 1978 al $15,45 \%$ en $1980^{26}$.

\subsection{Participación en la dirección del Sindicato}

Como hemos apuntado la afiliación posibilitaba la asunción de puestos dentro de los órganos de dirección de los sindicatos, cargos que las mujeres no solían ostentar o, cuando ello ocurría, sólo los ocupaban en muy baja proporción. Sin embargo, no puede decirse que no hubiera llegado a existir un deseo de que las mujeres se promocionaran dentro de CC.OO., deseo expresado por las militantes en el Congreso Constituyente y al que ponía voz Begoña San José en un artículo titulado "La mujer en CC.OO., a debate”, publicado en la Gaceta de Derecho Social en diciembre de 1976. En este mismo artículo, se recordaba que Raquel Soto, de la rama del metal, había reconocido en dicho Congreso que de las 19 personas que componían el Secretariado de la Unión Sindical de CC.OO. de Madrid, sólo 3 eran mujeres y:

“esto porque en la constitución de la Unión de Madrid se planteó el problema. Pero lo que es el colmo - había protestado la trabajadora - es que en el Secretariado Nacional de CC.OO no hay ni una mujer"27.

\footnotetext{
25 "CC.OO. de 3M: Hablan las trabajadoras" (noviembre 1980). En Gaceta Sindical, no 7, p. 32.

${ }^{26}$ San José, Begoña (marzo 1981): "8 de marzo día internacional de la mujer trabajadora". En Gaceta Sindical, n 10, p. 49.
} 
En octubre de 1979, Begoña San José (1979: 27), como miembro del Secretariado Confederal de CC.OO., hacía un llamamiento desde la prensa al sindicato con motivo de la renovación de cargos en el próximo Congreso. El objetivo de esta intervención era abrir los órganos de dirección a las trabajadoras, para equiparar su proporción a la de las mujeres que había en las bases. También desde Trabajadora, publicación de la Secretaría de la Mujer, ante este segundo Congreso Confederal de CC.OO. que se celebraría en 1981, se hacia un llamamiento mediante una propuesta de la Comisión de la Mujer que, junto a la programación de objetivos concretos que mejoraran la situación de las trabajadoras en el trabajo, creía que había que programar objetivos de incremento de participación de las mujeres en la actividad sindical, sobre todo la participación en los órganos de dirección de CC.OO., y ello implicaba una voluntad y un instrumento de mayor participación, de adecuación del sindicalismo a la medida y sensibilidad de todos. Esto afectaba también a la elección de Delegados al Congreso, que en 1978 sólo en el 9,4\% de los casos recayó sobre mujeres, a pesar de representar éstas el $30 \%$ de los afiliados a CC.OO. ${ }^{28}$

En 1981, CC.OO. declara que los varones constituían el 97\% del Consejo Confederal. UGT en 1982 evaluaba en un 93\% la presencia de hombres en su Comité Federal $^{29}$.

${ }^{27}$ Sánchez, M. y Montolio, S. (diciembre 1976): "La mujer en CC.OO. a debate”. En Gaceta de Derecho Social, $\mathrm{n}^{\circ} 67$ separata, pp. 26-28.

28 " $2^{\circ}$ Congreso de CC.OO. Aumentar la participación de las trabajadoras". Trabajadora, (mayo 1981), pp. 1-2.

${ }^{29}$ Martínez Ten, Carmen (1990): “La participación política de la mujer en España”. En Judith Astelarra (comp.), Participación política de las mujeres. Madrid: C.I.S., p. 55. 
Proporción de mujeres en diversos Órganos de dirección

\begin{tabular}{|l|c|}
\hline Secretariado Confederal & $5,2 \%$ \\
\hline Ejecutiva Confederal & $6,8 \%$ \\
\hline Consejo Confederal & $3 \%$ \\
\hline Ejecutiva Uniones Provinciales Regionales & $6 \%$ \\
\hline Ejecutiva Sindicatos & $20 \%$ \\
\hline Delegados de Empresa & $12 \%$ \\
\hline Trabajadoras Afiliadas a CC.OO & $30 \%$ \\
\hline Población Asalariada & $25 \%$ \\
\hline Población Activa & $29 \%$ \\
\hline Población Total & $52 \%$ \\
\hline
\end{tabular}

6. Fuente: San José, Begoña (octubre 1979): “Qué aportan y qué exigen las mujeres al sindicalismo”. En Gaceta de Derecho Social, $n^{\circ}$ 100, p. 27.

La estructura básica del sindicato está formada por federaciones de rama. En 1982, en las ejecutivas de tales federaciones las mujeres están presentes en diferentes proporciones, siendo mayores en aquellas ramas consideradas propiamente femeninas como enseñanza y sanidad.

Mujeres en las ejecutivas de las Federaciones de Rama de CC.OO.

\begin{tabular}{|l|c|c|}
\hline Federación & Número & Proporción \\
\hline Sanidad & 11 de 29 & 37,9 \\
\hline Enseñanza & 10 de 29 & 34,5 \\
\hline Administración Pública & 17 de 60 & 28,3 \\
\hline Textil & 8 de 29 & 27,6 \\
\hline Químicas & 4 de 29 & 13,8 \\
\hline Espectáculo & 3 de 23 & 13,0 \\
\hline Hostelería & 2 de 20 & 10,0 \\
\hline Comercio & 2 de 21 & 9,5 \\
\hline Alimentación & 2 de 28 & 7,1 \\
\hline Pensionistas & 1 de 20 & 5,0 \\
\hline
\end{tabular}

7. Fuente: "Secretaría de la Mujer de CC.OO" (1982). En Pilar Alcobendas Tirado: Datos sobre el trabajo de la mujer en España. Op. cit., p. 157. 


\section{Acción sindical a favor de la igualdad}

Las sindicalistas suelen mostrarse de acuerdo en que se primó la lucha antifranquista frente a las reivindicaciones específicas de género, ante la idea de que había que subordinarlo todo a los objetivos revolucionarios y las desigualdades se solventarían cuando la clase obrera llegara al poder. En el sindicato se reproducían los mismos esquemas que aparecían en la sociedad dando primacía al trabajo masculino y considerando el de la mujer como algo transitorio ${ }^{30}$. No se trataban aquellos problemas que surgían fuera del ámbito de la empresa, que permanecían en el "universo de lo

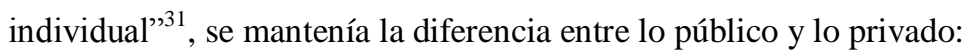

“el feminismo ni se podía nombrar. La relación con el feminismo era motivo de bronca segura. En el mundo sindical la cosa era absolutamente sangrante, y los problemas para que las mujeres participasen horrorosos. Lo que primaba en esos sectores era el tema de clase (...) los demás es tontería, ideas burguesas, de querer minar la unidad de clase, ${ }^{, 32}$.

Nuria Casals, miembro del Secretariado de la Confederación Nacional de Cataluña, en una entrevista, comentaba que si el sindicato quería agrupar a gente de vanguardia no podía permitir que se repitiera la situación de la mujer en la sociedad, por eso, debería representársela mejor en los organismos dirigentes, y existir organismos en que pudieran militar específicamente como mujeres de CC.OO. Habría que discutir en serio los problemas de la mujer, que siempre se posponían porque no se consideraban

\footnotetext{
${ }^{30}$ Escario, Pilar; Alberdi, Inés y López-Accotto, Ana Inés (1996): Lo personal es político. El Movimiento Feminista en la Transición. Madrid: Instituto de la Mujer, pp. 259-260.

${ }^{31}$ Méda, Dominique (2002): El tiempo de las mujeres. Madrid: Nacea, p. 46; Sullerot, Evelyne (1970): Historia y Sociología del Trabajo Feminino. Barcelona: Peninsula, p. 386.

${ }^{32}$ Barrio, Emilia (1996): Historia de las transgresoras. La transición de las mujeres. Barcelona: Icaria, pp. 65-70.
} 
urgentes y analizar los problemas en las diferentes ramas, porque la situación era diferente en cada una de ellas ${ }^{33}$.

Con todo, la Gaceta de Derecho Social daba cuenta de que, a pesar de las dificultades, las reivindicaciones femeninas se iban abriendo paso al igual que en los partidos políticos, y las demandas respecto al trabajo femenino se intensificaban en los mismos campos que lo habían hecho anteriormente. En las propuestas de ponencias para el Programa del Primer Congreso de la Confederación Sindical de CC.OO. se defendía:

- El derecho al trabajo sin ningún tipo de discriminación (igualdad de salarios, clasificación profesional y acceso a todas las categorías y profesiones).

- Valoración de la función social de la maternidad (repartir el cuidado de los hijos entre la pareja, maternidad libre y planificada, permisos para el cuidado de hijos indistintamente para el padre o la madre y servicios sociales que facilitasen la conciliación de la maternidad y el trabajo).

- Otra de las peticiones, reiteradas a lo largo de estos años, fue la necesidad de regular el servicio doméstico, algo que no se había solventado con la Ley de Relaciones Laborales ${ }^{34}$.

La difícil lucha de la aceptación por parte del sindicato de la inclusión de las propuestas de género dentro de sus programas se vio incrementada por las diferencias surgidas con los compañeros sindicalistas:

“...discriminación que no sería posible sin el consentimiento de los propios trabajadores y que llega a extremos como el que este año se firmen convenios con subidas inferiores para las mujeres" ${ }^{\prime 35}$.

\footnotetext{
${ }^{33}$ Sánchez, M. y Montolio, S. "La mujer en CC.OO. a debate. (Entrevista a Nuria Casals)". Op. cit., p. 28.

${ }^{34}$ San José, Begoña. "Mujer y juventud en el sindicalismo de clase”. Op. cit., pp. 20-21.
} 
Tampoco entre las mujeres todas las reivindicaciones tenían la misma aceptación, mientras la igualdad salarial era muy respaldada y también el reingreso al empleo de las casadas sometidas en el franquismo a excedencia forzosa por matrimonio, resultó menos comprendida la supresión de la dote a la trabajadora que abandonara el empleo al casarse, que se veía por algunas una pérdida, ya que el empleo lo iban a dejar de todas formas, reconocía Begoña San José (entrevista, Salamanca, 22 mayo de 2007).

A dichas discrepancias se añadían las de los sectores de mujeres que no consideraban que el sindicato tuviera que hacerse eco de las pretensiones feministas y pensaban que la creación de estructuras de exclusiva participación femenina dentro de la organización no fomentaba una integración real en el mundo sindical ${ }^{36}$.

El sindicato trató, por todos los medios, de borrar esa imagen de marginalidad, fomentando el trabajo de las Secretarias de la Mujer en materia de "empleo, reivindicaciones de servicios sociales, negociación colectiva, desarrollo legislativo y la garantía por parte de la organización del desarrollo de esas tareas ${ }^{, 37}$, e intentando que los grupos formados por mujeres se integraran dentro de la estructura del sindicato:

“garanticemos la discusión y la elaboración de alternativas a la problemática de la mujer, pero sin lanzar a las mujeres a estructuras paralelas, marginales. Que la lucha contra la discriminación se plantee de modo que sea asumida por el conjunto del Sindicato" 38 .

El trabajo realizado a través de las Secretarías - según opinión de Begoña San José (entrevista, Salamanca 22 mayo de 2007) - sirvió para incorporar las

${ }^{35}$ San José, Begoña (abril 1980): "La mujer trabajadora y la crisis". En Gaceta Sindical, no 1, p. 48.

${ }^{36}$ G. Villar, Conchi (enero-junio 2001): "Recuperar y repensar la memoria de las mujeres sobre la experiencia sindical". En Arenal, vol. 8, n 1, pp. 160-161.

${ }^{37}$ San José, Begoña (octubre 1979): "Qué aportan y qué exigen las mujeres al sindicalismo”. En Gaceta de Derecho Social, $\mathrm{n}^{\circ} 100$, p. 27.

${ }^{38}$ San José, Begoña: "Mujer y juventud en el sindicalismo de clase". Op. cit., p. 21. 
reivindicaciones feministas al sindicato e hizo que las trabajadoras sacaran a la luz injusticias y demandas hasta entonces ocultas, por ejemplo se producen las primeras denuncias de acoso sexual y maltrato en la pareja. La difusión que se dio a esta labor a través de la publicación de CC.OO., a pesar de que tenían una difusión limitada, de cuadros, contribuyó principalmente a que las reivindicaciones de las mujeres se asumieran más por el conjunto de la dirección del sindicato y no sólo por las militantes o por los miembros de la Secretaría de la Mujer.

\section{Disminución de la afiliación femenina}

A principios de los años 80, la militancia femenina en los sindicatos comenzó a disminuir. Dentro del sector industrial, solamente el 18,8\% de las mujeres estaban afiliadas, lo que representaba un $8 \%$ de los afiliados de este sector ${ }^{39}$.

Para Pilar Díaz Sánchez (2000: 331), fue el desencanto producido a raíz de los Pactos de la Moncloa (1977-1978), cuando los líderes sindicales son más proclives a gestionar el sistema económico que a democratizarlo, lo que llevó a las sindicalistas a abandonar sus cargos directivos en los sindicatos. Álvaro Soto Carmona también cree que los Pactos de la Moncloa resultaron perjudiciales para el sindicato, pero añade además causas internas y de organización ${ }^{40}$.

\footnotetext{
${ }^{39}$ Alcobendas Tirado, Pilar. Datos sobre el trabajo de la mujer en España. Op. cit., p. 152.

40 "La realidad fue que la dirección de CC.OO. antepuso dos razones para suscribir y defender los Pactos: sanear la economía para consolidar la democracia en primer lugar y confiar que los mismos iban en la estrategia diseñada por el PCE para que éste obtuviera cuotas de poder político en segundo término [...] El resultado fue beneficioso para la economía y la transición democrática pero tuvo efectos negativos desde un punto de vista sindical: descenso de la participación y movilización de los trabajadores, debilitamiento de los sindicatos, incumplimiento de los aspectos más beneficiosos para los trabajadores y pérdida de poder adquisitivo [...] Pero en el caso de CC.OO la caída de afiliación que se constató a finales de 1978 durante el año siguiente tiene sus causas, además de en el marco político, económico y social y en la política sindical del Gobierno, en las deficiencias internas y organizativas del sindicato que hace que no se pueda poner en práctica la estructura organizativa diseñada en el I Congreso (1978)". Soto Carmona, Álvaro: "Comisiones Obreras en la Transición y consolidación democrática". Op. cit, pp. 468-511.
} 
Las trabajadoras siempre alegaban su imposibilidad de dedicar muchas horas al sindicato y compatibilizarlo con las tareas del hogar, así como la incomprensión de maridos, novios y compañeros a la hora de facilitar y fomentar su participación.

No fue menos importante el desencanto originado por las acciones de las organizaciones sindicales, más centradas en asuntos económicos y acuerdos laborales que en la modificación de sus planteamientos, sin preocuparse de llevar a la práctica las reivindicaciones femeninas ni aportar soluciones a los problemas específicos. No se plantearon jamás la problemática del ama de casa en cuanto trabajadora, ni reflejaban los intereses femeninos. Así, no era de extrañar la ausencia de mujeres en estas organizaciones $^{41}$.

Desde la Secretaría de la Mujer del Secretariado de la CS de Comisiones Obreras se reconocían las aportaciones que en la defensa de las reivindicaciones de las mujeres y de su posición dentro del sindicato habían tenido la creación de las Secretarías de la Mujer, a pesar de su corto período de funcionamiento, ya que se hacía en 1978, pero también se destacaban algunos aspectos negativos como:

- La tendencia a nombrar Secretarías de la Mujer para cubrir el expediente de los nuevos tiempos, quitándose luego de encima la preocupación de seguir avanzando todo el Sindicato en la conciencia y la defensa de las reivindicaciones de la mujer.

- La tendencia a adjudicar la Secretaría de la Mujer a todas las mujeres que despuntan, evitando su promoción e incorporación a las responsabilidades generales. Esta era una nueva forma de super especialización y de marginación. ${ }^{42}$

\footnotetext{
${ }^{41}$ Astelarra, Judith (1990): "Las mujeres y la política". En Judith Astelarra (comp.): Participación política de la mujer. Op. cit., p. 15.

42 "Las Secretarías y las Comisiones de la Mujer en la organización de CC.OO.” (junio 1978). En Boletín del Secretariado Confederal de CC.OO. Suplemento Monográfico sobre la mujer trabajadora, pp. 3-4.
} 
Es el caso de Telefónica, las mujeres que habían participado activamente en los conflictos de empresa, no verán reconocidas sus reivindicaciones en las políticas sindicales. A la resistencia de los trabajadores masculinos a atenderlas se unía la no contemplación de la especificidad de sus problemas ${ }^{43}$.

"El modelo sigue siendo masculino, y a las mujeres se las invita a integrarse en ese modelo sin que puedan nunca ponerlo en cuestión. Cuando lo hacen y denuncian las discriminaciones que sufren, surgen las reticencias sindicales que, crecen con mucha frecuencia, como consecuencia de la voluntad de independencia de las mujeres" $" 44$.

La escasa representación de las mujeres en las instancias profesionales y sindicales no hacía más que reproducir desigualdades de género y generar otras nuevas ${ }^{45}$.

\section{Conclusiones}

El fin de la dictadura y el inicio de la transición democrática impulsaron a las trabajadoras a afiliarse a los sindicatos con la esperanza de que a la consecución de derechos económicos y laborales se sumaran la solución a los problemas de discriminación laboral que padecían. El cambio legislativo que ponía fin a las restricciones legales que menoscababa la libertad de acción y decisión de las mujeres, la legalización de partidos políticos y sindicatos, así como el reconocimiento y

\footnotetext{
43 Borderías, Cristina (1993): Entre líneas. Trabajo e identidad femenina en la España Contemporánea. Barcelona: Icaria, p. 246.

${ }^{44}$ Loiseau, Dominique (2000): "En cuanto a los sindicatos". En Christine Bard: Un siglo de antifeminismo. Madrid: Biblioteca Nueva, p. 303.

45 Lagrave, Rose-Marie (2000): “Una emancipación bajo tutela. Educación y trabajo de las mujeres en el siglo XX”. En G. Duby y M. Perrot (dirs.): Historia de las Mujeres, p. 549.
} 
desarrollo de la movilización social a favor de los derechos femeninos, fueron hechos decisivos a la hora de alentarlas a militar en los sindicatos, a pesar de todas las dificultades a las que se enfrentaban. Dificultades que provenían del entorno laboral: escasa incorporación al mercado laboral y precariedad en los empleos, del entorno familiar: conciliación de la vida familiar y laboral y nulo apoyo dentro de este ámbito para su dedicación sindical, junto a causas sociales y culturales: la consideración del salario femenino como un apoyo a la economía familiar y del sindicato como un espacio eminentemente masculino.

Este cambio de actitud respecto a su afiliación sindical no se tradujo en un aumento significativo de candidaturas femeninas en las elecciones sindicales celebradas en el periodo estudiado, ni tampoco en la obtención de cargos de dirección dentro del sindicato.

Comisiones Obreras, consciente de estas limitaciones, producidas en parte por la propia exclusión de las militantes, intentó, mediante la creación de las Secretarías de la Mujer, canalizar sus demandas e impulsar su participación e integración en el sindicato. Al mismo tiempo, procuraba hacer converger los intereses sindicales con los del movimiento feminista para que la doble militancia no fuera un obstáculo, pero no se alcanzaron los objetivos propuestos. El resultado fue la decepción de las sindicalistas, que empezaron a abandonar las centrales sindicales cuando, desde su percepción, entendieron que primaban más los intereses económicos y políticos que los que les afectaban a ellas particularmente, reivindicaciones que siempre quedaban relegadas ante otras consideradas más apremiantes y en la organización interna del sindicato se reproducía las mismas desigualdades que ellas soportaban cotidianamente. 


\section{BibLIOGRAFÍA}

- A. B. (marzo 1977): "Primeras Jornadas de la Mujer Trabajadora. Unidas contra toda la discriminación”. En Gaceta de Derecho Social, nº 70, pp. 8-9.

Alcobendas Tirado, P. (1993: Datos sobre el trabajo de la Mujer en España. Madrid: C.I.S.

- Astelarra, J. (1990): “Las mujeres y la política". En Judith Astelarra: Participación política de la Mujer. Madrid: C.I.S., pp. 7-22

- Barrio, E. (1996): Historia de las transgresoras. La transición de las mujeres. Barcelona: Icaria.

- Bellido, D. (1-7 diciembre 1977): "Feminismo sindicalista". En Mundo Obrero, $\mathrm{n}^{\circ}$ 48, p.16.

- Benito, A. (noviembre 1977): "La mujer ante las elecciones sindicales. Somos el 28 por 100 de la población activa”. En Gaceta de Derecho Social, n 78, p. 35-37.

- Borderías, C. (1993): Entre líneas. Trabajo e identidad femenina en la España Contemporánea. Barcelona: Icaria.

- “CC.OO. de 3M: Hablan las trabajadoras". (noviembre 1980). En Gaceta Sindical, n 7, p. 32.

- Di Febo, G. (1979): Resistencia y movimiento de mujeres en España, 1936-1976. Barcelona: Icaria.

- Díaz Sánchez, P. (2000): "La relación de las mujeres trabajadoras y los sindicatos durante el franquismo y la transición”. En A. I. Cerrada Jiménez y C. Segura Graíño (dirs.): Las mujeres y el poder. Representaciones y prácticas de vida. Madrid: Actas del - VII Coloquio A.E.I.H.M., pp. 323-336.

Durán, P. (diciembre 1980): “Textil: Triunfo en las grandes y pequeñas empresas”. En Gaceta Sindical, nº 8, p. 17-18.

- Durán Heras, M. A.: (1972): El trabajo de la mujer en España. Un estudio sociológico. Madrid: Tecnos. 
. (1977): Dominación, sexo y cambio social. Madrid: Cuadernos para el Diálogo.

Escario, P., Alberdi, I. y López-Accotto, A. I. (1996): Lo personal es político. El Movimiento Feminista en la Transición. Madrid: Instituto de la Mujer.

- F.B.P. (trad.) (agosto-septiembre 1975): "Una historia de mujeres" y "En la fábrica: compañera; en la casa: criada”. En Gaceta de Derecho Social, n 51-52 separata, pp. 129-132.

- Falcón, L. (2000): Mujer y poder político. Madrid: Kira Edit.

- G. Villar, C. (enero-junio de 2001).: "Recuperar y repensar la memoria de las mujeres sobre la experiencia sindical". En Arenal, vol. 8, n 1, pp. 155-175.

- Iglesias, M. A. (octubre 1972): "Liberación de la Mujer Obrera". En Gaceta de Derecho Social, n 17 , p. 23.

- Lagrave, R. M. (2000): "Una emancipación bajo tutela. Educación y trabajo de las mujeres en el siglo XX”. En G. Duby y M. Perrot (dirs.): Historia de las Mujeres. Madrid: Santillana, pp. 506-551

- "Las mujeres en la actividad sindical". (junio 1978). En Boletín del Secretariado Confederal de CC.OO. Suplemento monográfico sobre la Mujer Trabajadora, 4 páginas.

- "Las Secretarías y las Comisiones de la Mujer en la organización de CC.OO.”. (junio 1978). En Boletín del Secretariado Confederal de CC.OO. Suplemento Monográfico sobre la mujer trabajadora, 4 páginas.

- Loiseau, D. (2000): "En cuanto a los sindicatos". En C. Bard: Un siglo de antifeminismo. Madrid: Biblioteca Nueva, pp. 297- 305.

- Martínez Ten, C. (1990): “La participación política de la mujer en España”. En J. Astelarra (comp.): Participación política de la Mujer. Madrid: C.I.S., pp. 39-65

- Medá, D. (2002): El tiempo de las mujeres. Madrid: Narcea.

"Militancia sindical y feminista". (14-20 marzo 1977). En Mundo Obrero, no 10, p. 6.

N. P. (20 de diciembre 1969): “Más mujeres para el Partido". En Mundo Obrero, p. 7.

- Preston, P. (1989): España en crisis: evolución y decadencia del régimen de Franco. México: F.C.E.

- Rioboo, C. (marzo 1973): "Las enlaces sindicales”. En Gaceta de Derecho Social, no 22 , p. 14. 
- Salabert, M. (19 febrero 1977): "Primeras Jornadas de la Mujer trabajadora. La vanguardia insurgente del feminismo". En Triunfo, p. 16.

- San José, B.: . (abril 1978): "Mujer y juventud en el sindicalismo de clase". En Gaceta de Derecho Social, $\mathrm{n}^{\circ} 84$, p. 20-21. . (marzo 1979): "Día internacional de la mujer trabajadora". En Gaceta de Derecho Social, no 94 , p. 14-15.

. (octubre 1979): "Qué aportan y qué exigen las mujeres al sindicalismo". En Gaceta de Derecho Social, $\mathrm{n}^{\circ} 100$, pp. 26-27.

. (abril 1980) : "La mujer trabajadora y la crisis". En Gaceta Sindical, no 1, pp. 4748.

- (octubre 1980): "Elecciones Sindicales: Uno de cada cuatro electores son mujeres". En Gaceta Sindical, nº 6, p. 40.

. (marzo 1981): "8 de marzo día internacional de la mujer trabajadora". En Gaceta Sindical, nº10, pp. 48-50.

. (2007): "Las Secretarías Confederales de la Mujer de CC.OO.”. En VV.AA.: Trabajadora. Tres décadas de acción sindical por la igualdad de género (1977-2007). Madrid: Fundación $1^{\circ}$ de Mayo-Secretaría Confederal de la Mujer de CC.OO., pp. 7281.

- Sánchez, M. y Motolio, S. (diciembre 1976): "La mujer en CC.OO. a debate". “Entrevista a Nuria Casals". En Gaceta de Derecho Social, no 67 separata, pp. 25-28. “ $2{ }^{\circ}$ Congreso de CC.OO. Aumentar la participación de las trabajadoras". (mayo 1981). En Trabajadora, 4 páginas.

- Soto Carmona, A. (1994): “Comisiones Obreras en la transición y consolidación democrática". En David Ruiz (dir.): Historia de Comisiones Obreras (1958-1988). Madrid: Siglo Veintiuno, pp. 451-521.

- Sullerot, E. (1970) Historia y Sociología del Trabajo Femenino. Barcelona: Península. - Vanaclocha, M. M. (1999): “La mujer en el mundo laboral”. En VV.AA.: Españolas en la Transición. De excluidas a protagonistas (1973-1982). Madrid: Biblioteca Nueva, pp. 269-301. 